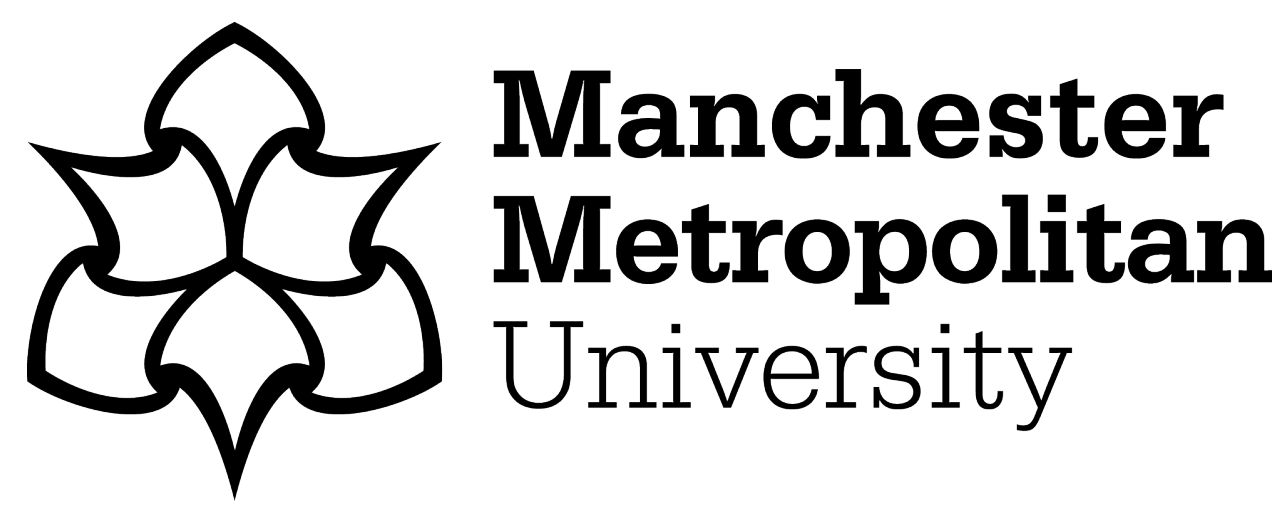

Liu, Yingyi (2017) Fraction magnitude understanding and its unique role in predicting general mathematics achievement at two early stages of fraction instruction. British Journal of Educational Psychology, 88 (3). pp. 345-362. ISSN 0007-0998

Downloaded from: https://e-space.mmu.ac.uk/625683/

Version: Accepted Version

Publisher: Wiley

DOI: https://doi.org/10.1111/bjep.12182

Please cite the published version 


\title{
Fraction magnitude understanding and its unique role in predicting general mathematics achievement at two early stages of fraction instruction
}

\author{
Yingyi Liu* \\ Department of Educational Psychology, Faculty of Education, The Chinese University \\ of Hong Kong, Shatin, Hong Kong
}

Background. Prior studies on fraction magnitude understanding focused mainly on
students with relatively sufficient formal instruction on fractions whose fraction
magnitude understanding is relatively mature.

Aim. This study fills a research gap by investigating fraction magnitude understanding in the early stages of fraction instruction. It extends previous findings to children with limited and primary formal fraction instruction.

Sample(s). Thirty-five fourth graders with limited fraction instruction and forty fourth graders with primary fraction instruction were recruited from a Chinese primary school.

Methods. Children's fraction magnitude understanding was assessed with a fraction number line estimation task. Approximate number system (ANS) acuity was assessed with a dot discrimination task. Whole number knowledge was assessed with a whole number line estimation task. General reading and mathematics achievements were collected concurrently and I year later.

Results. In children with limited fraction instruction, fraction representation was linear and fraction magnitude understanding was concurrently related to both ANS and whole number knowledge. In children with primary fraction instruction, fraction magnitude understanding appeared to (marginally) significantly predict general mathematics achievement I year later.

Conclusions. Fraction magnitude understanding emerged early during formal instruction of fractions. ANS and whole number knowledge were related to fraction magnitude understanding when children first began to learn about fractions in school. The predictive value of fraction magnitude understanding is likely constrained by its sophistication level.

Fraction magnitude understanding is a strong predictor of later proficiency in mathematics (e.g., Bailey, Hoard, Nugent, \& Geary, 2012; Torbeyns, Schneider, Xin, \& Siegler, 2015). Previous studies examined either children without sufficient fraction knowledge (e.g., Mack, 1995, 2001) or children who have completed most of their formal instruction in fractions (e.g., Siegler, Thompson, \& Schneider, 2011). Few studies focused on the development of fraction magnitude understanding in the emergent stage when children first begin formal fraction instruction (Resnick et al., 2016). Due to insufficient but

\footnotetext{
*Correspondence should be addressed to Yingyi Liu, Department of Psychology, The Education University of Hong Kong, 10 Lo Ping Road, Tai Po, Hong Kong (email: yyliu@eduhk.hk).
} 
ongoing instruction, children at this stage have immature or emergent fraction magnitude understanding and may exhibit distinct patterns compared to older children featured in previous studies. This study addresses this research gap by examining fraction magnitude understanding in children at the two earliest stages of formal fraction instruction. We recruited two groups of children - one received very limited instruction in fractions and the other received primary instruction (but not complete) in fractions. This study contributes to our knowledge of fraction magnitude understanding from a developmental perspective.

\section{The development of fraction magnitude understanding}

At an early age, children have real-life experiences to support their understanding of basic fraction concepts (e.g., Singer-Freeman \& Goswami, 2001). For example, children learn the semantic concept of $1 / 2$ when they share a cake with a friend. At age three, children start to show the ability to perform fraction calculations presented in the form of pictures (Mix, Levine, \& Huttenlocher, 1999). Their accuracy increases between ages 3 and 7 (Mix et al., 1999).

A crucial goal of fraction learning is understanding the magnitudes that fractions represent. Children with more than 1 year of formal instruction on fractions have demonstrated this ability (Iuculano \& Butterworth, 2011; Siegler et al., 2011). Recently, researchers investigated an early stage of formal fraction instruction in fourth graders (McMullen, Hannula-Sormunen, \& Lehtinen, 2014; McMullen, Laakkonen, HannulaSormunen, \& Lehtinen, 2015; Resnick et al., 2016; Vamvakoussi, 2015). Specifically, in studying fraction magnitude understanding, Resnick et al. found that fourth graders showed some level of fraction magnitude understanding. However, their participants seemed to have received some level of systematic instruction in fraction concepts and fraction comparison (Resnick et al., 2016, p. 3). Additionally, the study did not consider the contribution of the approximate number system (ANS) to fraction magnitude understanding or control the autoregressive effect of mathematics achievement when examining the predictive power of fraction magnitude understanding.

Our study extended existing knowledge by including children at two earlier stages of beginning fraction instruction and considering the effects of both the ANS and whole number knowledge. Formal fraction instruction is usually scaffolded step by step. Each step may lead to subtle changes in children's fraction magnitude understanding. To better understand the development of children's fraction magnitude understanding, it is necessary to take into account each instructional step.

\section{Predictors of fraction magnitude understanding}

Fraction magnitude understanding is closely related to two number systems, the ANS and whole number knowledge (Fazio, Bailey, Thompson, \& Siegler, 2014; Vukovic et al., 2014). Consequently, the present study focuses on these two core predictors. Furthermore, regarding the role of the ANS in fraction magnitude understanding, previous studies either did not compare the relative contributions of the ANS and whole number knowledge (Fazio et al., 2014; Resnick et al., 2016) or did not find a relationship (Jordan et al., 2013). The present study examined both ANS and whole number knowledge in a single model to examine their relative importance in predicting fraction magnitude understanding in the early stages of formal instruction of fractions. 


\section{Approximate number system}

The mental representation of numerical quantities (discrete or continuous) has been widely assumed to be supported by the ANS (e.g., Brannon \& Terrace, 1998; Wynn, 1992; Xu \& Spelke, 2000). Increasing evidence suggests that the ANS supports fraction learning (Meert, Grégoire, \& Noël, 2010; Sprute \& Temple, 2011). The ANS has been suggested to be related to ratio processing, a precursor of fraction magnitude understanding (Matthews, Lewis, \& Hubbard, 2016; McCrink \& Wynn, 2007; Meert, Grégoire, Seron, \& Noël, 2012).

Findings from developmental studies are mixed. Jordan et al. (2013) failed to find any significance of the ANS in predicting fraction concepts and procedures longitudinally from third grade to fourth grade. Apparently, some of the outcome variables in Jordan et al. involved part-whole understanding of fractions or the comparison of fractions with common denominators, which might have prompted children to use whole number knowledge instead of fraction magnitude understanding as their problem-solving strategy (Bonato, Fabbri, Umilta, \& Zorzi, 2007; Meert et al., 2010). It is possible that the ANS is related to fraction magnitude understanding, which is measured by the fraction number line estimation task (Siegler et al., 2011). Fazio et al. (2014) found that both symbolic fraction number line estimation and symbolic fraction comparison correlated with ANS acuity. This study would extend our knowledge of the predictive role of the ANS in fraction magnitude understanding to the beginning phases of formal fraction instruction.

\section{Whole number knowledge}

Whole number knowledge is the first type of symbolic mathematical knowledge to emerge in children (Gallistel \& Gelman, 1992; Gelman \& Gallistel, 1978). In learning whole number knowledge, children become equipped with mathematics principles that do not exist in the ANS - they learn that numbers are located along a number line from left to right in a linear manner (Siegler \& Opfer, 2003). The linear representation of whole numbers emerges early on and develops as children accumulate more experience and receive more formal instruction (Ashcraft \& Moore, 2012; Berteletti, Lucangeli, Piazza, Dehaene, \& Zorzi, 2010; Siegler \& Booth, 2004; Siegler \& Opfer, 2003).

Whole number estimation has been found to be a consistent predictor of fraction magnitude understanding across grades. Jordan et al. (2013) showed that when other general and math-specific factors were controlled, children's whole number estimation performance in third grade made the largest contribution in predicting their fraction concepts and procedures in fourth grade. Hansen et al. (2015) extended Jordan et al.'s findings to older children. Bailey, Siegler, and Geary (2014) found that whole number estimation in first grade predicted fraction estimation and comparison in seventh grade. The close relationship between whole number knowledge and fraction magnitude understanding can be explained by their shared cognitive foundations - the understanding of the magnitudes of symbolic numbers (Siegler et al., 2011).

\section{The predictive power of fraction magnitude understanding}

Understanding fractions is crucial for further numeracy development. Studies have revealed that fraction understanding predicts standardized and general mathematics achievements (Fazio et al., 2014; Torbeyns et al., 2015). Siegler et al. (2012) demonstrated that fifth graders' fraction magnitude understanding predicted their mastery of algebra and overall mathematics achievement in high school even after controlling for 
general cognitive abilities, family socio-economic status, and whole number knowledge. There are two possible explanations for the strong association between fraction understanding and mathematics achievement. On one hand, practically, concepts of fractions may serve a 'gatekeeper' function in which failure to master fractions is highly detrimental to later mathematics learning (Booth, Newton, \& Twiss-Garrity, 2014). On the other hand, theoretically, the integrated theory has proposed that the association between fraction magnitude understanding and overall mathematics achievement mirrored the close association between number sense and higher-level mathematics achievement (Dehaene, 1997).

It is unknown whether the associations between fraction magnitude understanding and overall mathematics score could be extended to children with limited or primary instruction. Does fraction magnitude understanding have predictive power when it is emergent? Some have hypothesized that the predictive power of fraction magnitude understanding lies partly in its ability to promote the learning of rational numbers, rules of arithmetic operations, pre-algebra, and algebraic equation solving (Booth et al., 2014; Siegler et al., 2011). Thus, the predictive power of fraction magnitude understanding might not be evident at the earliest stages of fraction learning, when it is not mature enough to support the understanding of higher-level mathematical concepts. Moreover, fraction magnitude understanding involves the ANS as well as understandings of whole numbers, fractions, and rational numbers in general. Without sufficient instruction, it may be difficult for children to intuitively integrate these areas of knowledge. In this sense, it is possible that only a relatively mature understanding of fractions can contribute to children's mathematics skills.

\section{The present study}

We posed three questions about fraction magnitude understanding from a developmental perspective. These three questions concern whether the theories of the development of fraction magnitude understanding can be extended to students at all stages of instruction. First, is fraction magnitude understanding present in children without sufficient formal instruction? Second, what is related to the individual differences in fraction magnitude understanding in children at the early stages of formal instruction of fractions? Third, does emergent fraction magnitude understanding predict general mathematics achievement in children without sufficient formal instruction? The widely used fraction number line estimation task was adopted in this study because it is rarely used by teachers for classroom instruction (Siegler et al., 2011).

Practically, it is helpful to know what occurs in the earliest phase of fraction instruction in typically developing children. This knowledge will help us design early intervention to prevent later learning difficulties in mathematics that may result from inadequate fraction understanding.

\section{Method}

\section{Participants}

This study was conducted in a Chinese primary school. This school is small-scaled with two classes per grade. Children were randomly assigned to two classes when they were admitted. The two classes involved in this study, both from Grade 4, were taught by the same Chinese reading and mathematics teachers. Participants were rewarded with small gifts after testing. 
In China, some cities have 5 years for primary school and 4 years for middle school. Some cities have 6 years for primary school and 3 years for middle school. These two educational systems may differ in the starting time of fraction instruction. The city where this study was conducted adopts the former system.

As reported by the mathematics teacher of the two classes, children are first introduced to fractions in grade 3 - instruction at this point is quite limited. Children are only taught that ' $1 / 2$ ' is a mathematic symbol for a type of numbers called fractions. They are taught to name fractions. Instruction is solely based on concrete and real-life scenarios such as splitting a cake. Moreover, children are taught with pictorial visual aid. For example, they learn that a circle shaded in half means $1 / 2$ and its shaded area is smaller than that in a circle shaded in $3 / 4$. However, children likely rely on the surface features of these pictures to make the comparison. The shaded area in $1 / 2$ would look conspicuously smaller than that in $3 / 4$. Given fractions without visual aid, children may not be able to compare the numerical magnitudes of fractions. Children at this point are not instructed on the mathematical meaning of fractions or their relationship to whole numbers. We call this type of instruction limited instruction. Limited instruction takes place for a week.

Near the end of the grade 4 , children are introduced to the definition, concepts, and mathematical meanings of fractions. They also learn to compare fractions with common components beyond the visual pictorial level. For example, they understand that $1 / 2$ equals to 0.5 or $50 \%$. We call this primary instruction. Primary instruction takes place for 6 weeks.

Among the two classes recruited, the first class with 35 children (20 boys, mean age $=120$ months, $S D=4.85$ months) was tested just before primary instruction started (Time 1[T1]). The only formal fraction instruction these children received had been limited instruction when they were in grade 3. This group is named the limited instruction group. In the following 1.5 months, primary instruction was given to all children. The second class with 40 children was tested immediately after primary instruction ( 20 boys, mean age $=122$ months, $S D=4.53$ months). This group is referred to as the primary instruction group. The reason why we adopted the betweensubject design is to prevent test-retest effect, which may overestimate children's gains in fraction magnitude understanding across the two instructional levels.

At T1, children's term scores in Chinese reading and mathematics were collected to indicate their general Chinese reading and mathematics achievement. The mathematics test at T1 involved mainly comparison and problem-solving questions with whole numbers. Some basic knowledge about fractions was tapped. One year later, at Time 2 [T2], general mathematics achievement was collected again. At T2, two children from the first class and three from the second class were missing due to school transfer. The mathematics test at T2 involved mainly comparison and problem-solving questions with fractions, decimals, and percentages. Whole number knowledge was involved to a smaller extent than it was in T1.

\section{Measures}

Fraction magnitude understanding

A $0-1$ fraction number line estimation task was used with stimuli adapted from Iuculano and Butterworth (2011), including 1/20, 1/9, 1/6, 1/5, 2/9, 1/4, 2/7, 1/3, 2/5, 4/9, 1/2, 4/7, $3 / 5,13 / 20,5 / 7,3 / 4,7 / 9,5 / 6,6 / 7$, and 19/20. Each child was given a booklet of papers with a $25 \mathrm{~cm}$ horizontal line printed across the middle. Above the mid-point of the 
number line was the number to be estimated. The order of these numbers was randomized for each student.

Three practice trials were given first. The children were asked to locate the numbers 50 , 30, and 90 on a $0-100$ number line. During the practice trials, the experimenter modelled her estimations on the blackboard, after which the formal test was presented. The children were instructed to make only one clear mark on the line to indicate their answer. No rulers or other measuring equipment were allowed. No time limit was set.

\section{Approximate number system}

Approximate number system acuity was assessed with Panamath software version 1.22 (Halberda, Mazzocco, \& Feigenson, 2008), which was performed on a computer set at the 12-year-old level to avoid ceiling effect (Jordan et al., 2013). The number of dots ranged from 5 to 21, and the colours involved were yellow and blue. Non-numerical variables were controlled to ensure that participants made their judgement based on the number of the dots rather than other cues. The participants pressed the ' $F$ ' key or the ' $\mathrm{J}$ ' key to indicate whether the left or the right side of the screen had more dots, respectively.

\section{Whole number knowledge}

A 0-1,000 whole number line estimation task was used with stimuli taken from Siegler and Opfer (2003), including 2, 4, 6, 18, 25, 71, 86, 230, 390, 780 and 810. Other details were identical to the fraction number line estimation task. This task was conducted right after the fraction number line estimation task. No practice trials were given as all children showed sufficient knowledge of the experimental procedure.

\section{Procedure}

The two number line estimation tasks were group-administered paper-and-pencil tasks; they were given to all children in the classrooms. Children were tested with the ANS measure in small groups in the school computer room. The tasks were administered over two consecutive school days.

\section{Data analysis}

Regression models were conducted with Mplus with MLR estimator (Muthén \& Muthén, 1998-2010). Missing data were addressed with full information maximum likelihood estimation.

\section{Results}

To evaluate ANS acuity, $w$ and RT were standardized and then summed to obtain $w+\mathrm{RT}$ to control for the speed-accuracy trade-off (Fazio et al., 2014). For the number line estimation task, estimation accuracy was assessed by percentage absolute error (PAE): PAE $=\mid$ Estimate-Estimated Quantity $\mid /$ Scale of Estimates. Smaller PAE indicates more accurate estimates on a number line (Siegler \& Booth, 2004). The linearity of the estimation was evaluated by conducting a regression model in which the children's estimates were regressed against the objective magnitudes. $R$ square of the model was 
used as the index for the linearity of estimation (Siegler \& Booth, 2004). A composite score of the number line tasks was calculated by transferring the PAE and linearity scores into $z$-scores and combining them together. Because the reading and mathematics measures were not standardized tests, the scores were transformed into $z$-scores. The descriptive statistics and correlation matrix are reported in Table 1 and Table 2, respectively. ANS acuity and whole number knowledge correlated significantly with fraction magnitude understanding for both groups.

Independent $t$-test analyses revealed that the two groups showed no significant differences in reading achievement (T1), mathematics achievement (T2), ANS acuity ( $w$ ) and whole number knowledge (PAE and linearity). They had marginal differences in mathematics achievement (T1) and reaction time on the ANS measure (both $p s=.04$ ). Considering that they were taught by the same reading and mathematics teachers, assigned the same homework in most cases, administered the same term tests, came from the same community and showed no significant differences on most measures, we assumed that the two groups of children were comparable to a large extent.

\section{Fraction magnitude understanding}

Some evidence suggests that the limited instruction group did not perform randomly. In Siegler and Pyke (2013), the average PAE on the same task for 6th and 8th graders was 16\%. In Resnick et al. (2016), the PAE on the same task was $19.87 \%$ for fifth graders. Our subjects were younger, but our results paralleled theirs with older children with more knowledge of fractions.

The first research question was addressed by analysing whether the children's representation of fractions was linear. At the group level, the fits of the linear and logarithmic functions to the group median estimates were examined. For each of the 20 stimuli, we compared whether children's median estimates were closer to the predicted values by the linear or logarithmic function (Siegler \& Booth, 2004). The scatter plots of group medians of estimates were displayed in Figures 1 and 2. Both groups of children's median estimates were a better fit with the linear function, $F(1,38)=38.47, p<.01$. The

Table I. Means and standard deviations of general school achievement and measures

\begin{tabular}{|c|c|c|c|c|}
\hline & \multicolumn{2}{|c|}{ Limited instruction group } & \multicolumn{2}{|c|}{ Primary instruction group } \\
\hline & M & $S D$ & M & $S D$ \\
\hline Reading (TI) & 92.47 & 4.21 & 88.88 & 11.40 \\
\hline Mathematics (TI) & 89.31 & 5.45 & 83.30 & 16.59 \\
\hline Mathematics (T2) & 89.64 & 8.38 & 85.03 & 11.80 \\
\hline \multicolumn{5}{|c|}{ Approximate number system (TI) } \\
\hline$w$ & 0.17 & 0.05 & 0.20 & 0.08 \\
\hline Reaction time & 667.59 & 88.52 & 708.76 & 77.22 \\
\hline \multicolumn{5}{|c|}{ Whole number line estimation (TI) } \\
\hline PAE & 0.08 & 0.06 & 0.08 & 0.05 \\
\hline Linearity & 0.92 & 0.08 & 0.88 & 0.13 \\
\hline \multicolumn{5}{|c|}{ Fraction number line estimation $(\mathrm{TI})$} \\
\hline PAE & 0.19 & 0.12 & 0.11 & 0.11 \\
\hline Linearity & 0.43 & 0.41 & 0.72 & 0.35 \\
\hline
\end{tabular}

Note. $\mathrm{PAE}=$ percentage absolute error. 
Table 2. Correlations between age, school achievement, approximate number system, whole number knowledge, and fraction magnitude understanding

\begin{tabular}{|c|c|c|c|c|c|c|c|}
\hline & I & 2 & 3 & 4 & 5 & 6 & 7 \\
\hline \multicolumn{8}{|l|}{ Limited instruction group } \\
\hline I. Age & - & & & & & & \\
\hline 2. Reading (TI) & .053 & - & & & & & \\
\hline 3. Mathematics (TI) & -.148 & .004 & - & & & & \\
\hline 4. Mathematics (T2) & $-.357^{*}$ & .142 & .129 & - & & & \\
\hline $\begin{array}{l}\text { 5. Approximate } \\
\text { number system }(\mathrm{TI})\end{array}$ & -.025 & -.249 & -.229 & -.001 & - & & \\
\hline $\begin{array}{l}\text { 6. Whole number } \\
\text { knowledge }(\mathrm{TI})\end{array}$ & .178 & .101 & .174 & .110 & -.270 & - & \\
\hline $\begin{array}{l}\text { 7. Fraction magnitude } \\
\text { understanding }(\mathrm{TI})\end{array}$ & -.023 & -.034 & .050 & .121 & $-.574 * * *$ & $.393^{*}$ & - \\
\hline \multicolumn{8}{|l|}{ Primary instruction group } \\
\hline I. Age (TI) & - & & & & & & \\
\hline 2. Reading (TI) & -.166 & - & & & & & \\
\hline 3. Mathematics (TI) & -.137 & $.88 I^{* * * *}$ & - & & & & \\
\hline 4. Mathematics (T2) & .009 & $\left..73\right|^{* * * *}$ & .876 *** & - & & & \\
\hline $\begin{array}{l}\text { 5. Approximate } \\
\text { number system (TI) }\end{array}$ & -.103 & -.217 & -.267 & -.294 & - & & \\
\hline $\begin{array}{l}\text { 6. Whole number } \\
\text { knowledge (TI) }\end{array}$ & -.036 & .288 & $.355^{*}$ & .277 & $-.335^{*}$ & - & \\
\hline $\begin{array}{l}\text { 7. Fraction magnitude } \\
\text { understanding }(\mathrm{TI})\end{array}$ & .009 & $.599 * * *$ & $.663^{* * *}$ & $.752^{* * * *}$ & $-.353^{*}$ & $.373^{*}$ & - \\
\hline
\end{tabular}

Notes. ${ }^{*} p<.05 ; * * p<.001$.

effect of instructional level was not significant, $F(1,38)=.021, p=.885$. The interaction term was significant, $F(1,38)=5.07, p=.030$.

For each individual, the estimates on all items were regressed against actual magnitudes according to the linear and logarithmic functions (Berteletti et al., 2010; Booth \& Newton, 2012; Booth \& Siegler, 2006). In the limited instruction group, the linear function accounted for $43 \%$ of the variance in estimates, whereas the logarithmic function accounted for $37 \%$. In the primary instruction group, individuals' estimates showed a relatively strong linear pattern (mean $R^{2}=72 \%$ ). In contrast, the fit of the logarithmic

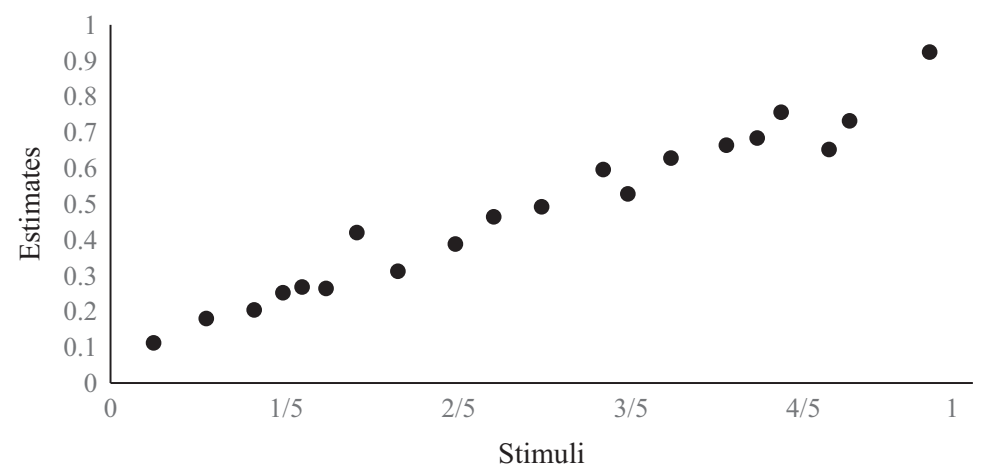

Figure I. Group means of estimates on the fraction estimation task for the limited instruction group. 


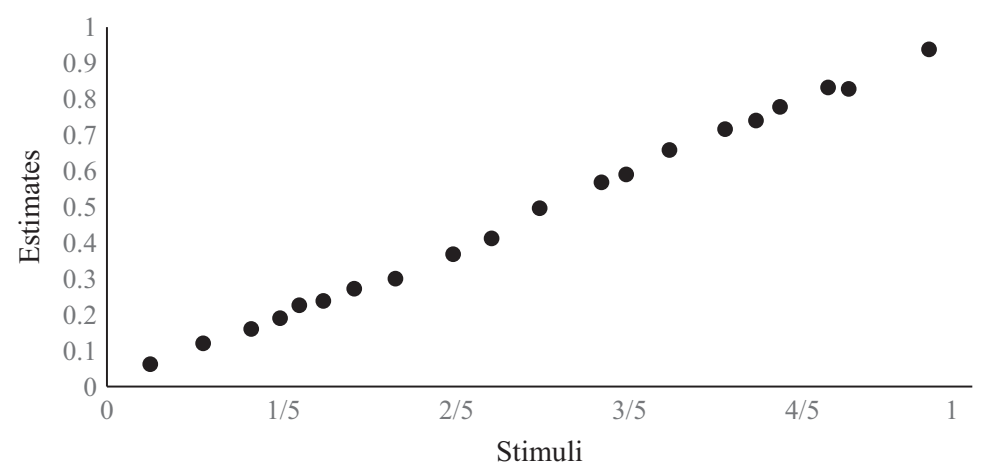

Figure 2. Group means of estimates on the fraction estimation task for the primary instruction group.

Table 3. Type of representation in the $0-I$ number line task in each group

\begin{tabular}{lcc}
\hline & Limited instruction group & Primary instruction group \\
\hline Linear representation & 17 & 33 \\
Logarithmic representation & 2 & 1 \\
None & 16 & 6 \\
\hline
\end{tabular}

Note. Cell values represent the number of cases in each pattern.

function was $61 \%$. Analyses with pattern of estimates (linear vs. logarithmic) as withinsubject factor and instructional level (limited instruction vs. primary instruction) as between-subject factor were performed. Children's mathematics achievement at T1 was included as a covariate. The main effect of instructional level was significant $(p<.01)$. The interaction between the pattern of estimates and instructional level was significant $(p<.01)$. Post-hoc analyses showed the magnitude of the difference between the two models to be .055 in the limited group and .113 in the primary group (both $p s<.01$ ).

Furthermore, a best estimation pattern (linear or logarithmic) was assigned to each child (Sella, Berteletti, Brazzolotto, Luncageli, \& Zorzi, 2013). An individual's estimation pattern was considered linear if the linear function had a higher $R^{2}$. It was considered logarithmic if the logarithmic function had a higher $R^{2}$. If both models were not significant, the individual was classified as non-representational. Table 3 shows that the number of children in each pattern of estimates varied significantly with instructional level, $\chi^{2}(2, N=75)=9.71, p<.01$.

\section{Predictors of fraction magnitude understanding}

Table 4 shows that in the limited instruction group, both the ANS and whole number knowledge predicted additional variance in the individual differences in fraction magnitude understanding beyond age, reading, and mathematics achievement. However, in the primary instruction group, no significant predictors were found.

\section{Predictive power of fraction magnitude understanding}

Table 5 shows that the predictive power of fraction magnitude understanding was found to be marginally significant $(p=.052$ when PAE score was used) or significant (both 


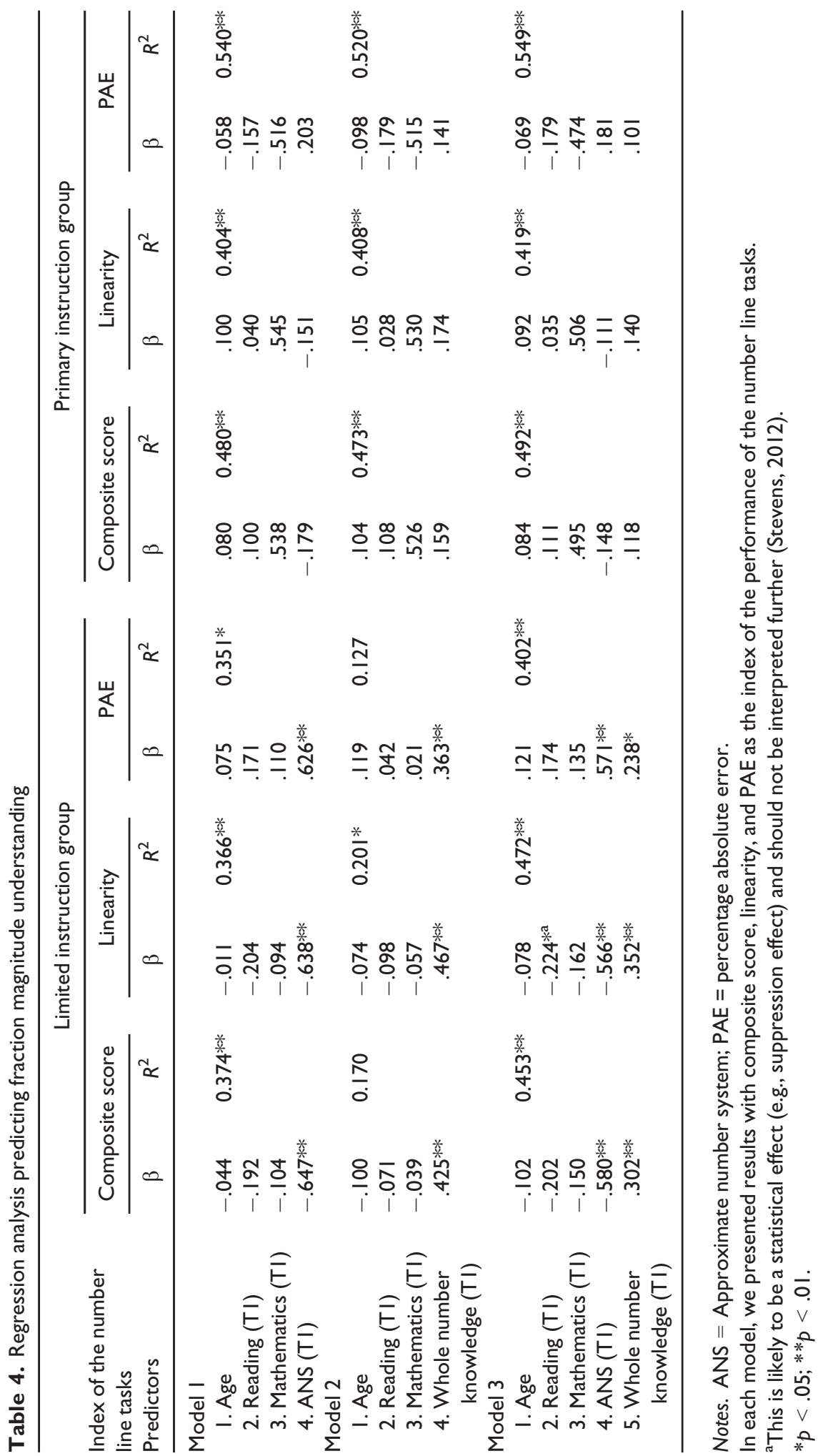


$p s<.05$ when the linearity score or a composite score was used) only in the primary instruction group, but this pattern did not hold in the limited instruction group.

\section{Discussion}

Our findings demonstrated that even with quite limited formal instruction, children's knowledge of fractions was linear and predicted by their ANS acuity and whole number knowledge above and beyond the contributions of age, reading, and mathematics achievement. The longitudinal predictive power of fraction magnitude understanding was found only in children with primary instruction in fractions but not in children with limited instruction.

\section{Fraction magnitude understanding in children with limited instruction}

It is striking to see that the mental representation of fractions was linear in children with very limited instruction in fractions. Previously, the linear fraction representation was only observed in older children who had had more instruction (Iuculano \& Butterworth, 2011; Siegler et al., 2011). We provided two possible explanations, which are not mutually exclusive requiring further empirical evidence to verify.

The first explanation is that children may use whole number knowledge as an aid to solve the fraction estimation task. Whole number knowledge involves arranging numbers sequentially and linearly on a line (e.g., Siegler \& Opfer, 2003). This way of arranging numbers may be similarly applied to fractions. Also, whole number estimation involves an understanding of the meaning of number symbols. Arabic digits or written number words are culturally invented symbols, the meanings of which are achieved by mapping onto mental magnitude codes (Dehaene, 1997; Gallistel \& Gelman, 1992, 2000; Gelman \& Gallistel, 1978). This mapping ability develops between 6 and 8 years of age (Mundy \& Gilmore, 2009). The access to the magnitude codes of whole numbers is found to be automatic around age 9 (Van Galen \& Reitsma, 2008). When children start learning fractions (at around age 10), the established mapping between symbols and the ANS may help children map fraction symbols onto the magnitudes in the ANS in a systematic way.

The second explanation is that the representation of symbolic fractions may develop in a different fashion than the logarithmic-to-linear developmental progression of whole numbers. For whole numbers, smaller numbers are more frequently encountered in our daily lives than larger numbers. Thus, children represent smaller numbers more accurately than they do larger numbers (Dehaene, 1997). This explains the logarithmic pattern of whole number representation at the early stages of whole number knowledge development. However, this may not be the case for fractions. Siegler et al. (2011) suggested that the representational pattern of fractions would not be logarithmic during development because the frequency of fractions encountered in our daily lives is not systematically related to their magnitudes. Smaller fraction values (e.g., 1/97) are not more commonly seen in our daily lives than larger ones (e.g., 3/4).

\section{ANS, whole number knowledge and fraction magnitude understanding}

The significant role of the ANS found in the present study dovetails with previous findings demonstrating the role of the ANS in supporting both whole number and rational number knowledge (Fazio et al., 2014; Siegler et al., 2011). Our findings lend support to the 


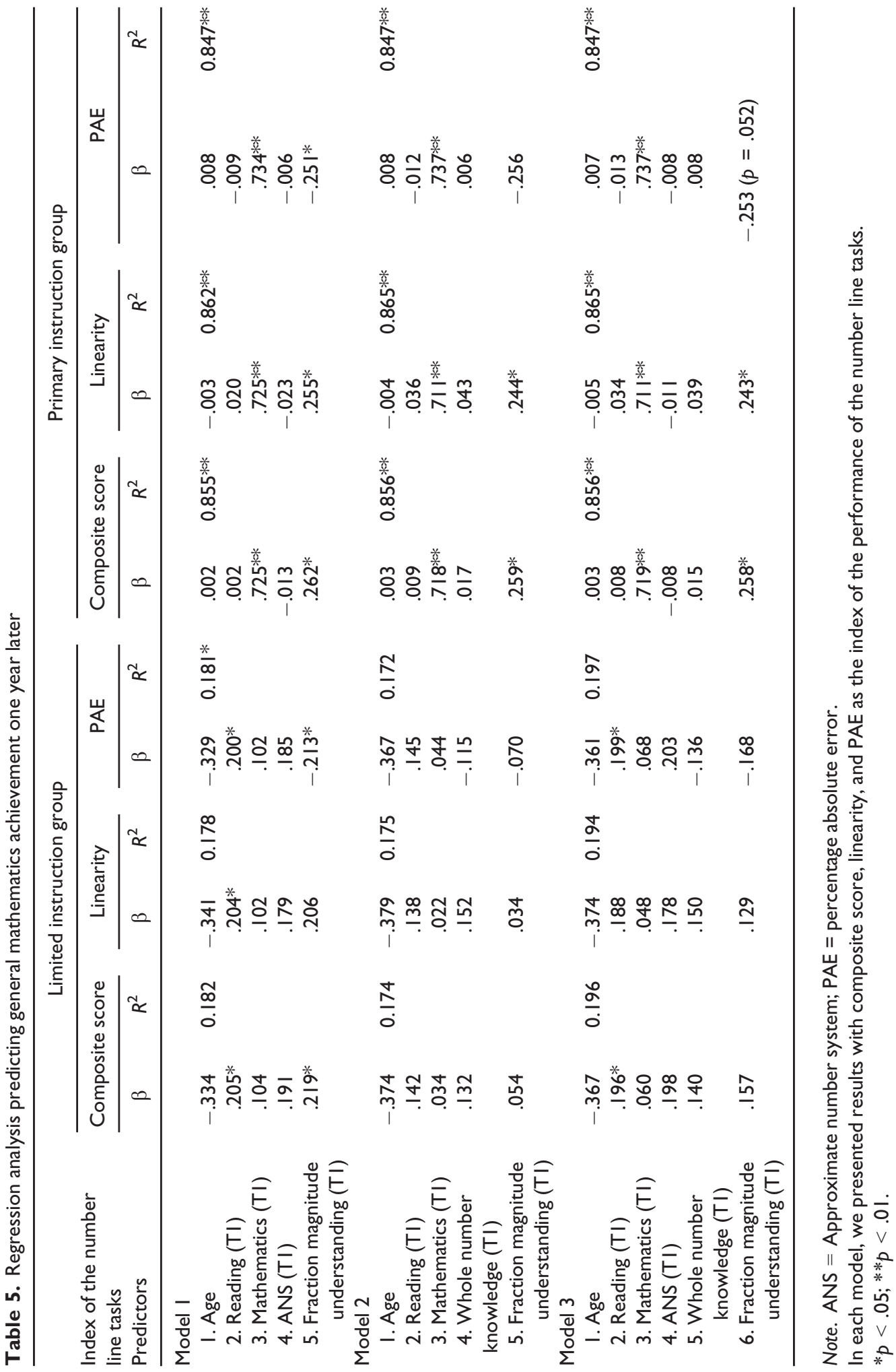


hypothesis that number sense is fundamental in the development of symbolic mathematical thinking (e.g., Chen \& Li, 2014; Halberda et al., 2008; Inglis, Attridge, Batchelor, \& Gilmore, 2011; Jordan, Glutting, \& Ramineni, 2010; Libertus, Feigenson, \& Halberda, 2011; Piazza et al., 2010; Starr, Libertus, \& Brannon, 2013). Moreover, our findings revealed that in the early development of fraction magnitude understanding in the school setting, both ANS and whole number knowledge played important roles.

By contrast, in the primary instruction group, both ANS acuity and whole number knowledge were significantly correlated with fraction magnitude understanding but failed to reach significance when included in a single model. This may suggest that the ANS and whole number knowledge may both have influences on children's fraction magnitude understanding but their contributions were not unique to each other. The overlapping contribution of the ANS and whole number knowledge can be explained by their common nature of representing magnitude (Dehaene, 1997). There is evidence showing that as children develop a mature understanding of fractions, they learn to integrate whole numbers and fractions into a single rational number system and interpret both as magnitudes in the ANS (e.g., DeWolf, Bassok, \& Holyoak, 2015; Siegler et al., 2011). The children in the primary instruction group were perhaps progressing towards this mature rational number system in which a number of skills, including the ANS and whole number knowledge, were integrated. Therefore, when the two were considered simultaneously, we could not extricate one single significant predictor of individual differences. Alternatively, instead of the ANS and whole number knowledge coming together to account for the variance, it could be that conceptual knowledge of fractions simply renders both abilities less important for the fraction number line estimation task.

\section{Fraction magnitude understanding predicts mathematics achievement}

Consistent with previous studies (Fazio et al., 2014; Resnick et al., 2016; Torbeyns et al., 2015), our finding shows that fraction magnitude understanding longitudinally (marginally) predicts general mathematics achievement in the primary instruction group. This finding seems to support the hypothesis that the symbolic understanding of numbers is related to general mathematics achievement (Siegler et al., 2011). By contrast, for the limited instruction group, the predictive power of fraction magnitude understanding on mathematics achievement was not significant. The contrast between the two groups suggests that the predictive value of fraction magnitude understanding is likely constrained by its sophistication level.

In the limited instruction group, children's linear representation of fractions indicates some degree of fraction magnitude understanding. However, their understanding might not be consolidated - their estimates on the fraction number line task were less accurate or linear than those made by the primary instruction group. Formal instruction on the concepts of fractions provides children with a deeper understanding of fraction magnitudes, allowing them to make more accurate estimates of fractions on the mental number line. Also, children gain a firm understanding of the relationship between whole numbers and fractions on the number line, which may facilitate the learning of algebra which requires more advanced magnitude understanding of the number system.

It should be noted that when PAE was used as the sole indicator of the fraction number line estimation task, the predictive power of the task was marginal. PAE and linearity are two different indicators of the number line estimation task. The use of PAE versus linearity has seldom been addressed in past studies. Linearity has been a useful developmental predictor in the past, but that fraction magnitude understanding can be gauged by other 
measures (e.g., PAE), as well as other tasks (e.g., comparisons). Some researchers used linearity as the sole indicator because it showed superior predictive value in predicting mathematics achievement (Booth \& Newton, 2012; Booth et al., 2014). The present study showed that providing PAE score is important as well because it shows a different pattern than that shown by linearity scores. PAE, to some extent, may be a more accurate indicator. A more linear representation of numbers is not necessarily a correct one. Even though the children in the primary instruction group showed a more linear pattern, their knowledge may not be as mature as assumed. Their fraction understanding may need to be enhanced to support more advanced rational number problem-solving.

\section{Limitation}

First, the underlying problem-solving strategies used by the limited group was not clear. Although the group's performance was comparable to that of older children in other studies, their fraction magnitude understanding may not be comparable. They may use $1 / 2$ as an anchor or focus only on numerators or denominators (Ni \& Zhou, 2005). Also, although our results suggested that the ANS and whole number knowledge supported the children's performance, further research is needed to explore the mechanism involved. Second, our sample size was relatively small. Future studies with larger sample sizes are needed to verify the present findings. Third, school instruction varies greatly across regions and countries. The generalizability of the present results may be limited. Fourth, although our between-subject design has the strength of being free of the test-retest effect, it has a limitation. The two groups of children may not be identical in all aspects, which challenges the validity in comparing their performances. Table 2 indicates that the two groups had differences in correlation matrices concerning mathematics achievements, ANS, whole number knowledge and fraction magnitude understanding, so it brings up the possibility that the differences observed in the two groups arise from some unmeasured differences between them.

In conclusion, the present study revealed how fraction magnitude understanding developed when instruction took place in two steps. It also revealed fraction magnitude understanding's relationships with the ANS, whole number knowledge, and later general mathematics achievement. The linear representation of fractions was found to be present quite early. Both the ANS and whole number knowledge had significant roles in supporting fraction learning in children with limited instruction. Furthermore, the predictive power of fraction magnitude understanding was observed only in children with primary instruction of fraction.

Practically, the findings suggest that a linear representation of fractions at the starting point of instruction may be predictive of satisfactory later mathematics achievement and should be emphasized by educators and parents. However, as the teachers in the present study indicated, very little instruction was provided on positioning fractions on a number line. Teachers and parents may use activities (e.g., linear numerical board games) to explicitly teach fraction magnitude understanding (Ramani \& Siegler, 2008; Ramani, Siegler, \& Hitti, 2012; Siegler \& Ramani, 2009), which may help promote children's overall mathematics achievement in the long run. The lack of a linear representation of fractions may lead to delays in higher-level mathematics skills such as fraction arithmetic computations, pre-algebra, and algebraic equation solving. Interventions may be developed to teach the linear representation of fractions. Both the ANS and whole number knowledge should be given sufficient 
attention (Park \& Brannon, 2013; Siegler \& Ramani, 2009). Furthermore, teachers should explicitly explain the similarities and differences in ways to discriminate between magnitudes in non-symbolic quantities, whole numbers, fractions, and mixed numbers (Woodward, 2017).

\section{References}

Ashcraft, M. H., \& Moore, A. M. (2012). Cognitive processes of numerical estimation in children. Journal of Experimental Child Psychology, 111, 246-267. https://doi.org/10.1016/j.jecp. 2011.08.005

Bailey, D. H., Hoard, M. K., Nugent, L., \& Geary, D. C. (2012). Competence with fractions predicts gains in mathematics achievement. Journal of Experimental Child Psychology, 113, 447-455. https://doi.org/10.1016/j.jecp.2012.06.004

Bailey, D. H., Siegler, R. S., \& Geary, D. C. (2014). Early predictors of middle school fraction knowledge. Developmental Science, 17, 775-785. https://doi.org/10.1111/desc.12155

Berteletti, I., Lucangeli, D., Piazza, M., Dehaene, S., \& Zorzi, M. (2010). Numerical estimation in preschoolers. Developmental Psychology, 46, 545-551. https://doi.org/10.1037/a0017887

Bonato, M., Fabbri, S., Umilta, C., \& Zorzi, M. (2007). The mental representation of numerical fractions: Real or integer? Journal of Experimental Psychology: Human Perception \& Performance, 33, 1410-1419. https://doi.org/10.1037/0096-1523.33.6.1410

Booth, J. L., \& Newton, K. J. (2012). Fractions: Could they really be the gatekeeper's doorman? Contemporary Educational Psychology, 37, 247-253. https://doi.org/10.1016/j.cedpsych. 2012.07.001

Booth, J. L., Newton, K. J., \& Twiss-Garrity, L. K. (2014). The impact of fraction magnitude knowledge on algebra performance and learning. Journal of Experimental Child Psychology, 118, 110-118. https://doi.org/10.1016/j.jecp.2013.09.001

Booth, J. L., \& Siegler, R. S. (2006). Developmental and individual differences in pure numerical estimation. Developmental Psychology, 42, 189-201. https://doi.org/10.1037/0012-1649.41.6. 189

Brannon, E. M., \& Terrace, H. S. (1998). Ordering of the numerosities 1 to 9 by monkeys. Science, 282, 746-749. https://doi.org/10.1126/science.282.5389.746

Chen, Q., \& Li, J. (2014). Association between individual differences in non-symbolic number acuity and math performance: A meta-analysis. Acta Psychologica, 148, 163-172. https://doi.org/ 10.1016/j.actpsy.2014.01.016

Dehaene, S. (1997). The number sense: How the mind creates mathematics. New York, NY: Oxford University Press.

DeWolf, M., Bassok, M., \& Holyoak, K. J. (2015). From rational numbers to algebra: Separable contributions of decimal magnitude and relational understanding of fractions. Journal of Experimental Child Psychology, 133, 72-84. https://doi.org/10.1016/j.jecp.2015.01.013

Fazio, L. K., Bailey, D. H., Thompson, C. A., \& Siegler, R. S. (2014). Relations of different types of numerical magnitude representations to each other and to mathematics achievement. Journal of Experimental Child Psychology, 123, 53-72. https://doi.org/10.1016/j.jecp. 2014.01.013

Gallistel, C. R., \& Gelman, R. (1992). Preverbal and verbal counting and computation. Cognition, 44 (1-2), 43-74. https://doi.org/10.1016/0010-0277(92)90050-R

Gallistel, C. R., \& Gelman, R. (2000). Non-verbal numerical cognition: From reals to integers. Trends in Cognitive Sciences, 4(2), 59-65. https://doi.org/10.1016/S1364-6613(99)01424-2

Gelman, R., \& Gallistel, C. R. (1978). The child's understanding of number. Cambridge, MA: Harvard University Press.

Halberda, J., Mazzocco, M. M., \& Feigenson, L. (2008). Individual differences in non-verbal number acuity correlate with maths achievement. Nature, 455, 665-668. https://doi.org/10.1038/ nature 07246 
Hansen, N., Jordan, N. C., Fernandez, E., Siegler, R. S., Fuchs, L., Gersten, R., \& Micklos, D. (2015). General and math-specific predictors of sixth-graders' knowledge of fractions. Cognitive Development, 35, 34-49. https://doi.org/10.1016/j.cogdev.2015.02.001

Inglis, M., Attridge, N., Batchelor, S., \& Gilmore, C. (2011). Non-verbal number acuity correlates with symbolic mathematics achievement: But only in children. Psychonomic Bulletin \& Review, 18, 1222-1229. https://doi.org/10.3758/s13423-011-0154-1

Iuculano, T., \& Butterworth, B. (2011). Understanding the real value of fractions and decimals. The Quarterly Journal of Experimental Psychology, 64, 2088-2098. https://doi.org/10.1080/ 17470218.2011.604785

Jordan, N. C., Glutting, J., \& Ramineni, C. (2010). The importance of number sense to mathematics achievement in first and third grades. Learning and Individual Differences, 20(2), 82-88. https://doi.org/10.1016/j.lindif.2009.07.004

Jordan, N. C., Hansen, N., Fuchs, L. S., Siegler, R. S., Gersten, R., \& Micklos, D. (2013). Developmental predictors of fraction concepts and procedures. Journal of Experimental Child Psychology, 116(1), 45-58. https://doi.org/10.1016/j.jecp.2013.02.001

Libertus, M. E., Feigenson, L., \& Halberda, J. (2011). Preschool acuity of the approximate number system correlates with school math ability. Developmental Science, 14, 1292-1300. https://doi. org/10.1111/j.1467-7687.2011.01080.x

Mack, N. K. (1995). Confounding whole-number and fraction concepts when building on informal knowledge. Journal for Research in Mathematics Education, 26, 422-441. https://doi.org/10. $2307 / 749431$

Mack, N. K. (2001). Building on informal knowledge through instruction in a complex content domain: Partitioning, units, and understanding multiplication of fractions. Journal for Research in Mathematics Education, 32, 267-295. https://doi.org/10.2307/749828

Matthews, P. G., Lewis, M. R., \& Hubbard, E. M. (2016). Individual differences in nonsymbolic ratio processing predict symbolic math performance. Psychological Science, 27, 191-202. https:// doi.org/10.1177/0956797615617799

McCrink, K., \& Wynn, K. (2007). Ratio abstraction by 6-month-old infants. Psychological Science, 18, 740-745. https://doi.org/10.1111/j.1467-9280.2007.01969.x

McMullen, J., Hannula-Sormunen, M. M., \& Lehtinen, E. (2014). Spontaneous focusing on quantitative relations in the development of children's fraction knowledge. Cognition and Instruction, 32, 198-218. https://doi.org/10.1080/07370008.2014.887085

McMullen, J., Laakkonen, E., Hannula-Sormunen, M., \& Lehtinen, E. (2015). Modeling the developmental trajectories of rational number concept (s). Learning and Instruction, 37 , 14-20. https://doi.org/10.1016/j.learninstruc.2013.12.004

Meert, G., Grégoire, J., \& Noël, M. (2010). Comparing the magnitude of two fractions with common components: Which representations are used by 10- and 12-year-olds? Journal of Experimental Child Psychology, 107, 244-259. https://doi.org/10.1016/j.jecp.2010.04.008

Meert, G., Grégoire, J., Seron, X., \& Noël, M. (2012). The mental representation of the magnitude of symbolic and nonsymbolic ratios in adults. The Quarterly Journal of Experimental Psychology, 65, 702-724. https://doi.org/10.1080/17470218.2011.632485

Mix, K. S., Levine, S. C., \& Huttenlocher, J. (1999). Early fraction calculation ability. Developmental Psychology, 35(1), 164-174. https://doi.org/10.1037/0012-1649.35.1.164

Mundy, E., \& Gilmore, C. K. (2009). Children's mapping between symbolic and nonsymbolic representations of number. Journal of Experimental Child Psychology, 103, 490-502. https:// doi.org/10.1016/j.jecp.2009.02.003

Muthén, L. K., \& Muthén, B. O. (1998-2010). Mplus user's guide (vol. 6). Los Angeles, CA: Author.

Ni, Y., \& Zhou, Y. D. (2005). Teaching and learning fraction and rational numbers: The origins and implications of whole number bias. Educational Psychologist, 4O(1), 27-52. https://doi.org/ $10.1207 / \mathrm{s} 15326985$ ep4001_3

Park, J., \& Brannon, E. M. (2013). Training the approximate number system improves math proficiency. Psychological Science, 24, 2013-2019. https://doi.org/10.1177/095679761348 2944 
Piazza, M., Facoetti, A., Trussardi, A. N., Berteletti, I., Conte, S., Lucangeli, D., ... Zorzi, M. (2010). Developmental trajectory of number acuity reveals a severe impairment in developmental dyscalculia. Cognition, 116(1), 33-41. https://doi.org/10.1016/j.cognition. 2010.03.012

Ramani, G. B., \& Siegler, R. S. (2008). Promoting broad and stable improvements in low-income children's numerical knowledge through playing number board games. Child Development, 79, 375-394. https://doi.org/10.1111/j.1467-8624.2007.01131.x

Ramani, G. B., Siegler, R. S., \& Hitti, A. (2012). Taking it to the classroom: Number board games as a small group learning activity. Journal of Educational Psychology, 104, 661-672. https://doi.org/ $10.1037 / \mathrm{a} 0028995$

Resnick, I., Jordan, N. C., Hansen, N., Rajan, V., Rodrigues, J., Siegler, R. S., \& Fuchs, L. S. (2016). Developmental growth trajectories in understanding of fraction magnitude from fourth through sixth grade. Developmental Psychology, 52, 746-757. https://doi.org/ 10.1037/dev0000102

Sella, F., Berteletti, I., Brazzolotto, M., Luncageli, D., \& Zorzi, M. (2013). Number line estimation in children with developmental dyscalculia. Learning Disabilities: A Contemporary Journal, 11 (2), 41-49.

Siegler, R. S., \& Booth, J. L. (2004). Development of numerical estimation in young children. Child Development, 75, 428-444. https://doi.org/10.1111/j.1467-8624.2004.00684.x

Siegler, R. S., Duncan, G. J., Davis-Kean, P. E., Duckworth, K., Claessens, A., Engel, M., ... Chen, M. (2012). Early predictors of high school mathematics achievement. Psychological Science, 23, 691-697. https://doi.org/10.1177/0956797612440101

Siegler, R. S., \& Opfer, J. E. (2003). The development of numerical estimation: Evidence for multiple representations of numerical quantity. Psychological Science, 14, 237-250. https://doi.org/ 10.1111/1467-9280.02438

Siegler, R. S., \& Pyke, A. A. (2013). Developmental and individual differences in understanding of fractions. Developmental Psychology, 49, 1994-2004. https://doi.org/10.1037/a0031200

Siegler, R. S., \& Ramani, G. B. (2009). Playing linear number board games-but not circular onesimproves low-income preschoolers' numerical understanding. Journal of Educational Psychology, 101, 545-560. https://doi.org/10.1037/a0014239

Siegler, R. S., Thompson, C. A., \& Schneider, M. (2011). An integrated theory of whole number and fractions development. Cognitive Psychology, 62, 273-296. https://doi.org/10.1016/j.cogpsych. 2011.03.001

Singer-Freeman, K. E., \& Goswami, U. (2001). Does half a pizza equal half a box of chocolates?: Proportional matching in an analogy task. Cognitive Development, 16, 811-829. https://doi. org/10.1016/S0885-2014(01)00066-1

Sprute, L., \& Temple, E. (2011). Representations of fractions: Evidence for accessing the whole magnitude in adults. Mind, Brain, and Education, 5(1), 42-47. https://doi.org/10.1111/j.1751228X.2011.01109.x

Starr, A., Libertus, M. E., \& Brannon, E. M. (2013). Number sense in infancy predicts mathematical abilities in childhood. Proceedings of the National Academy of Sciences of the United States of America, 110, 18116-18120. https://doi.org/10.1073/pnas.1302751110

Stevens, J. P. (2012). Applied multivariate statistics for the social sciences. New York: Routledge.

Torbeyns, J., Schneider, M., Xin, Z., \& Siegler, R. S. (2015). Bridging the gap: Fraction understanding is central to mathematics achievement in students from three different continents. Learning and Instruction, 37, 5-13. https://doi.org/10.1016/j.learninstruc.2014.03.002

Vamvakoussi, X. (2015). The development of rational number knowledge: Old topic, new insights. Learning and Instruction, 37, 50-55. https://doi.org/10.1016/j.learninstruc.2015. 01.002

Van Galen, M. S., \& Reitsma, P. (2008). Developing access to number magnitude: A study of the SNARC effect in 7-to 9-year-olds. Journal of Experimental Child Psychology, 101(2), 99-113. https://doi.org/10.1016/j.jecp.2008.05.001 
Vukovic, R. K., Fuchs, L. S., Geary, D. C., Jordan, N. C., Gersten, R., \& Siegler, R. S. (2014). Sources of individual differences in children's understanding of fractions. Child Development, 85, 1461-1476. https://doi.org/10.1111/cdev.12218

Woodward, J. (2017). The concept of magnitude and what it tells us about how struggling students learn fractions. Journal of Learning Disabilities, 50(6), 640-643. https://doi.org/10.1177/ 0022219416659445

Wynn, K. (1992). Addition and subtraction by human infants. Nature, 358, 749-750.

Xu, F., \& Spelke, E. S. (2000). Large number discrimination in 6-month-old infants. Cognition, 74(1), B1-B11. https://doi.org/10.1016/S0010-0277(99)00066-9

Received 8 June 2016; revised version received 7 July 2017 